\title{
Outcomes following pancreatic resections - results and challenges of an Austrian university hospital compared to nationwide data and international centres
}

\author{
Benno Cardini · Florian Primavesi (D) - Manuel Maglione - Julia Oberschmied • Luisa Guschlbauer • \\ Silvia Gasteiger - Stefanie Kuscher - Thomas Resch · Rupert Oberhuber · Christian Margreiter · \\ Stefan Schneeberger · Dietmar Öfner · Stefan Stättner
}

Received: 14 January 2019 / Accepted: 16 March 2019 / Published online: 3 April 2019

(C) The Author(s) 2019

\begin{abstract}
Summary
Background Despite clear advances in decreasing postoperative mortality below $4 \%$ after pancreatic resections in experienced centres, specific morbidity according to standardized definitions still remains high. While some recent multicentre studies have reported on complications after pancreatic surgery in Austria, detailed outcome data from single highvolume centres over longer time-periods are scarce. This study provides an in-depth picture of patient characteristics, indications, morbidity and mortality after pancreatic surgery in an Austrian tertiary referral centre.

Methods All patients undergoing curative intent resection between 2010 and 2017 at the Medical University of Innsbruck were evaluated. Patient characteristics and procedural details, overall and specific complications including postoperative pancreatic fistula (POPF), delayed gastric emptying (DGE) and postpancreatectomy haemorrhage $(\mathrm{PPH})$ rates according to accepted definitions are reported. Outcomes after pancreatic head resections, distal pancreatectomy and other types of resections are compared. Factors associated with severe and overall morbidity are evaluated by logistic regression modelling.

Results A total of 343 patients underwent pancreatic resection, at a median of 64 years (53\% males). Most
\end{abstract}

B. Cardini · F. Primavesi, MD $(\bowtie) \cdot$ M. Maglione .

J. Oberschmied - L. Guschlbauer · S. Gasteiger · S. Kuscher ·

T. Resch · R. Oberhuber · C. Margreiter · S. Schneeberger ·

D. Öfner $\cdot$ S. Stättner

Department of Visceral, Transplantation and

Thoracic Surgery, Medical University of Innsbruck,

Anichstraße 35, 6020 Innsbruck, Austria

florian.primavesi@i-med.ac.at common indications were pancreatic or bile-duct carcinoma (52\%), benign/precursor lesions $(22 \%)$ and neuroendocrine tumours (11\%). The 90-day mortality was $2 \%$; 90-day overall/severe morbidity was $66.2 \% / 22.4 \%$. POPF grade B/C occurred in $19.3 \%$, PPH in $17.5 \%$ and DGE in $14.3 \%$. Male gender was associated with severe morbidity, body mass index and procedures other than distal resections with overall morbidity. POPF and PPH were major causes for relaparotomy.

Conclusions Pancreatic resections in our centre are performed with low mortality, although morbidity still represents a relevant clinical problem, especially POPF and PPH.

Keywords Pancreatic surgery · Morbidity · Complications · Failure to rescue

Main novel aspects

- In-depth analysis of all consecutive pancreatic resections over 8 years in an Austrian high-volume centre.

- Postoperative 90-day mortality was $2 \%$ in this timeperiod, ranging amongst state-of-the art units worldwide, compared to $7.5 \%$ in-hospital mortality nationwide in Austria (in 2017). In our department, a low failure-to-rescue rate of $2.2 \%$ was achieved, although meticulous documentation revealed a high postoperative morbidity of $66 \%$.

- Postoperative pancreatic fistula and haemorrhage represent the major challenges in terms of severe complications after pancreatic surgery and their sequelae are the main reasons for relaparotomy, readmission and failure to rescue. 


\section{Introduction}

Mortality following pancreatic resection (PR) has decreased over the last decades with current rates ranging between 2 and $6 \%$ in high-volume centres. In contrast, morbidity in this surgical field still remains high, and increases depending on the type as well as complexity of the surgical intervention with overall complication rates of up to $60 \%[1,2]$. Major morbidity and associated sequelae occur in up to $30 \%$ and are mostly related to specific complications typical for pancreatic surgery including postoperative pancreatic fistula (POPF), delayed gastric emptying (DGE) and post-pancreatectomy haemorrhage (PPH) [3]. In order to enable international comparability, many different classification systems for these aforementioned specific complications have been proposed. Hereby the definitions established by the International Study Group of Pancreatic Surgery (ISGPS) have gained broad acceptance especially in experienced centres $[3,4]$. According the ISGPS definition, POPF develops in $10-15 \%$ of patients after pancreatoduodenectomy (PD) and in 10-30\% of cases undergoing distal pancreatectomy (DP) [2]. DGE after PD is seen in 20-50\% of all patients and $\mathrm{PPH}$ develops in $4-16 \%$ of patients after PD and in $2-3 \%$ after DP ([2]; Table 1). Early recognition and adequate management of potentially lethal complications represents the major challenge. In this context, centre volume has been identified as a factor of crucial importance, whereby increased surgical experience as well as availability of multidisciplinary approaches towards complication management helps to prevent failure to rescue (FTR) and consequently death $[5,6]$.

Most recently available, official nationwide postoperative mortality rates after pancreatic surgery in Austria from 2017 are displayed in Fig. 1 [7]. In summary, for a total population of 8.8 million, 60 hospitals performed any type of pancreatic procedure, and the nationwide in-hospital mortality was $7.5 \%$. The median number of procedures was 10.5 (range 1-96), and 38 hospitals performed less than 20 procedures, 9 hospitals between 20 and 29 procedures and 13 units at least 30 procedures. The in-hospital mortality rate in departments performing less than 10 pancreatic procedures per year was $12 \%$ compared to $8.1 \%$ in those with $20-29$ procedures and $5.8 \%$ in hospitals with at least 30 procedures.

Table 1 Rates of complications specific for pancreatic surgery, as described by [2, 39]

\begin{tabular}{|l|l|l|}
\hline Specific complication & PD (\%) & DP (\%) \\
\hline POPF & $10-15$ & $10-30$ \\
\hline DGE & $20-50$ & 24 \\
\hline PPH & $4-16$ & $2-3$ \\
\hline
\end{tabular}

$D G E$ Delayed gastric emptying, $D P$ distal pancreatectomy, $P D$ pancreatoduodenectomy, $P O P F$ postoperative pancreatic fistula, $P P H$ post-pancreatectomy haemorrhage

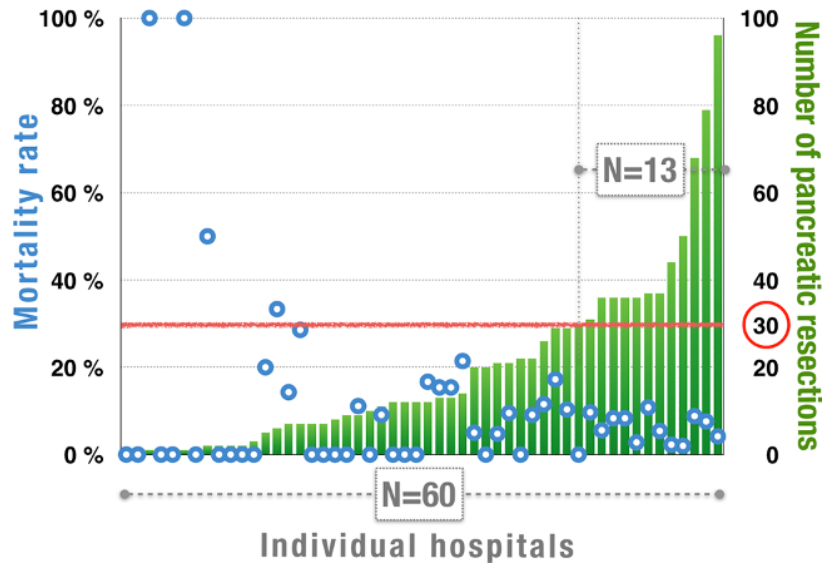

Fig. 1 Nationwide numbers of pancreatic surgical procedures performed per hospital in Austria (2017). Green bars show the number of resections per unit performed in one year (range 1-96). Blue dots represent individual mortality rates per centre. The red line depicts a cut-off level of 30 or more procedures performed per hospital. In these units $(n=13)$, the overall mortality was $5.8 \%$ compared to $10 \%$ in all other hospitals $(n=47)$

Regarding publications on detailed postoperative mortality and morbidity after PR in Austria, multicentre data were recently reported in one prospective trial and two retrospective registries on pancreatic cancer and neuroendocrine tumour resections [8-10]. These publications all included only medium- to high-volume centres, with a resulting postoperative 30 - to 90 day mortality of 2.4 to $3.5 \%$, showing that pancreatic surgery in specialized Austrian units is performed within internationally accepted safety range. However, detailed analysis of indications, types of resections and postoperative morbidity and mortality over a long time-period from single high-volume centres may help to further define areas for potential improvements [11-13].

Thus, we aimed to analyse 90-day morbidity and mortality of patients undergoing PR at our institution and to compare these outcomes with nationwide results and international outcomes published in the literature. Furthermore, we intended to identify potential parameters including patient characteristics and comorbidities, indications as well as technical aspects of surgery, which may indicate patients at higher risk for postoperative complications.

\section{Materials and methods}

\section{Patient cohort}

All patients undergoing PR between 2010 and 2017 at the Department of Visceral, Transplant and Thoracic Surgery at the Medical University of Innsbruck were evaluated. Exclusion criteria were: patients who did not undergo resection after exploration, cases with pancreatic biopsies only, duodenal malignancies without need for pancreatic resection, and patients 
receiving palliative procedures such as gastroenteric bypass surgery. Patients with chronic pancreatitis were included when the procedure included removal of pancreatic parenchyma (such as Frey's procedure or resection of chronically infected pseudocysts). Analysis was conducted from our institution's auditable database on pancreatic surgery, which has been retrospectively recorded from 2010-2015 and prospectively from thereon. The database ethics protocol was reviewed by the ethics committee of Medical University of Innsbruck (AN2016-0128), waiving the need for individual informed consent. The following parameters are reported in this study: patient characteristics including age, body mass index (BMI), American Society of Anaesthesiology (ASA) scoring, pre-existing diabetes, history of cardiovascular disease (coronary heart disease, myocardial infarction, severe carotid stenosis or peripheral arterial disease), pulmonary disease (chronic obstructive pulmonary disease, asbestosis, etc.), metabolic diseases (metabolic syndrome or untreated thyroid disease), previous history of or ongoing smoking and alcohol consumption, previous other malignancies or surgery. Surgical details included indication for surgery, type and extent of surgery including vascular and other organ resection, postoperative morbidity and mortality (in-hospital and 90-day). Pancreatic fistula is defined according to the International study group for pancreatic fistula (ISGPF) 2005 classification, DGE according to the ISGPS 2007 definition and PPH according the ISGPS 2007 classification [14-16]. Postoperative 90-day mortality was validated with the official national mortality registry of Statistics Austria [17]. FTR was defined as the number of patients who died from complications divided by the number of complications as previously e.g. reported by Tamirisa et al. [18]. Patients who died from rapid disease progression within 90 days were not included in FTR calculations.

\section{Statistical analysis}

Patient characteristics and surgical details are presented as numbers with frequencies (\%) or medians with standard deviation (SD). Differences in numbers and types of procedures per year were assessed using the $\chi^{2}$ and Fisher's Exact Test. The Kruskal-Wallis test and $\chi^{2}$ and Fisher's Exact Test were used for comparisons between outcomes of the three different groups of procedures (PD versus DP versus others). To estimate the risk of different clinical and procedural factors for occurrence of severe or overall complications, univariable and multivariable logistic regression was performed with the enter method. $P$-values $<0.05$ were considered significant throughout all analyses. SPSS version 21.0 (IBM Corporation, Chicago, IL, USA) was used for statistical calculations.

\section{Results}

\section{Patient demographics and indications for surgery}

In total, 343 patients underwent pancreatic resection between 2010 and 2017 in our institution. Patient characteristics, indications for and type of surgery are summarized in Table 2. The median age was 64 years (SD 13.9) and $53.4 \%$ of patients were male. The most common indication were malignant tumours (pancreatic carcinoma or distal cholangiocarcinoma; $51.9 \%$ ) and benign indications $(22.2 \%)$, which included benign cystic or precursor lesions (pancreatic intraepithelial neoplasm [PanIN] 17.2\%) other than IPMN and chronic pancreatitis (5\%). Regarding comorbidities, $11(3.2 \%)$ and $53(15.5 \%)$ patients had pre-existing type 1 or type 2 diabetes, respectively. A total of 137 patients $(39.9 \%)$ presented with any type of chronic metabolic disease, 197 (57.4\%) with cardiovascular disease and 68 (19.8\%) with pulmonary disease. Active smoking was reported in 103 (30.4\%) cases. Alcohol consumption was declared as occasional by 116 patients (34.5\%) and as regular/abusive by 24 patients $(7.1 \%)$. About $20 \%(n=69)$ of patients had experienced previous other malignancies and 169 patients $(49.3 \%)$ had undergone previous abdominal surgery.

\section{Surgical procedures}

The number of resections per year increased over time from $n=38$ in 2010 to $n=59$ in 2017, as did the rate of laparoscopic procedures ( 0 to $10.2 \%$; $p=0.023$ ). Most frequently a PD was performed $(57.4 \%)$, followed by DP (with or without splenectomy; $35.2 \%$; Table 2). The numbers of different types of surgical procedures per year are displayed in Fig. 2 (PD versus DP and others). Vascular resections were performed in 44 (12.8\%) patients (19 arterial and 31 venous resections). Concurrent (partial) resection of additional organs other than the spleen was conducted in 50 patients (14.6\%), most commonly involving the gallbladder, liver and stomach.

\section{Postoperative surgical outcomes}

Overall, postoperative complications within 90-day occurred in 227 patients $(66.2 \%)$, with $22.4 \%$ of patients $(n=77)$ having severe complications (>3a). Detailed frequencies according to the Clavien-Dindo classification were as follows: grade I: 31 (9\%); grade 2: 67 (19.5\%); grade 3a: 52 (15.2\%); grade 3b: 43 (12.5\%); grade $4 \mathrm{a}: 23(6.7 \%)$; grade $4 \mathrm{~b}: 5(1.5 \%)$; grade $5: 6$ $(1.7 \%=$ in-hospital mortality). Relaparotomy was required in 51 cases $(14.9 \%)$. The 90 -day mortality was $2 \%(n=7)$ and causes of death were multiorgan failure $(n=4)$, rapid disease progression $(n=2)$ and cardiac decompensation $(n=1)$. No significant difference regarding 90-day mortality or severe complications 
could be recorded over the years. The median postoperative length of stay was 15 days (SD: 16.4; range: $6-137)$ with a readmission rate of $18.4 \%(n=63)$. In the whole cohort, clinically relevant POPF occurred in 66 patients (19.3\%; type B: $15.2 \%$, type C: $4.1 \%$ ) and management was interventional in 38 (11.1\%) and surgical in $13(3.8 \%)$ cases. $\mathrm{PPH}$ was recorded in $17.5 \%$ of patients: grade A: $5 \%(n=17)$; grade $\mathrm{B}$ : $5.8 \%(n=20)$; grade C: $6.7 \%(n=23)$. Patients experiencing $\mathrm{PPH}$ ultimately underwent relaparotomy in the further course in $58.3 \%$ of cases, compared to $5.7 \%$ of patients without PPH $(p<0.001)$. DGE occurred in $14.3 \%$ of patients: grade A: $6.4 \% \quad(n=22)$; grade B: $3.2 \%(n=11)$; grade C: $4.7 \%(n=16)$. Other common postoperative complications included peripancreatic, intraabdominal fluid collections $(n=122$; $35.6 \%)$, pleural effusion ( $n=77 ; 22.4 \%)$, surgical site infections $(n=46 ; 13.4 \%)$, and ileus $(n=9 ; 2.6 \%)$. One quarter of all patients received postoperative transfusions $(n=84 ; 24.5 \%$; missing=37). The FTR rate was $2.2 \%$ after occurrence of any complication (5 of 227 patients), $6.7 \%$ after PPH (4 of 60 ) and $1.5 \%$ after clinically relevant POPF (1 of 66).

Detailed information on the type and severity of morbidity according to the type of resection are presented in Table 3. There were no significant differences between types of resection and overall/ severe morbidity as well as 90-day mortality. However, resections other than pancreatoduodenectomy had a considerable higher rate of clinically relevant POPF $(p=0.004)$ and less frequent pleural effusion $(p<0.001)$. In terms of management, there was no significant difference between the rate of relaparotomy, median length of stay and readmission rate, but requirement for transfusion was more common after pancreatoduodenectomy and other procedures compared to distal resections.

\section{Factors associated with postoperative severe morbidity}

Table 4 shows factors associated with risk for postoperative severe morbidity (including death). The only factor associated with severe complications in both univariable and multivariable analysis was male gender (hazard ratio [HR] 1.92; 95\% confidence interval $[C I]: 1.09-3.38 ; p=0.024)$. The rate of severe complications was significantly higher in male $(27.9 \%)$ compared to female patients $(16.3 \% ; p=0.010)$. Interestingly neither age, nor comorbidities, type of indication or resection, as well as additional procedures like vascular resection or other organ resection were significantly associated with increased rates of severe complications. When evaluating overall morbidity, the only risk factor associated with a higher rate of complications in multivariable analysis was higher BMI (HR 1.12; 95\% CI 1.05-1.20; $p<0.001$ ), while distal resections compared to other types of surgery
Table 2 Patient characteristics, indications and surgical procedures

\begin{tabular}{|c|c|}
\hline & $n(\%)$ \\
\hline \multicolumn{2}{|l|}{ Patient characteristics } \\
\hline \multicolumn{2}{|l|}{ Age (years) } \\
\hline$<60$ & $132(38.5)$ \\
\hline $60-69$ & $89(25.9)$ \\
\hline $70-79$ & $107(31.2)$ \\
\hline$\geq 80$ & $15(4.4)$ \\
\hline Gender: male & $183(53.4)$ \\
\hline \multicolumn{2}{|l|}{$B M I$ (missing = 1) } \\
\hline$<20$ & $31(9)$ \\
\hline $20-24.9$ & $152(44.3)$ \\
\hline$\geq 25$ & $159(46.4)$ \\
\hline \multicolumn{2}{|l|}{ ASA score (missing $=46$ ) } \\
\hline 1 & $36(12.1)$ \\
\hline 2 & $180(60.6)$ \\
\hline 3 & $80(26.9)$ \\
\hline 4 & $1(0.3)$ \\
\hline \multicolumn{2}{|l|}{ Indications } \\
\hline Benign tumour, PanIN or pancreatitis & 76 (22.2) \\
\hline IPMN & $31(9)$ \\
\hline NET & $39(11.4)$ \\
\hline Carcinoma & $178(51.9)$ \\
\hline Others (Metastases, Sarcoma, etc.) & $19(5.5)$ \\
\hline \multicolumn{2}{|l|}{ Type of resection } \\
\hline$P P P D$ & $185(53.9)$ \\
\hline PRPD (Kausch-Whipple) & $12(3.5)$ \\
\hline Distal pancreatectomy + splenectomy & $77(22.4)$ \\
\hline Distal pancreatectomy (spleen preserving) & $44(12.8)$ \\
\hline Enucleation & $9(2.8)$ \\
\hline Total pancreatectomy & $7(2.0)$ \\
\hline Frey procedure & $4(1.2)$ \\
\hline Pseudocyst resection & $3(0.9)$ \\
\hline Central resection & $2(0.6)$ \\
\hline \multicolumn{2}{|l|}{ Further procedural aspects } \\
\hline Laparoscopic & $22(6.4)$ \\
\hline \multicolumn{2}{|l|}{ Resection of vessels } \\
\hline Arterial & $19(5.5)$ \\
\hline Venous (PV, SMV, VC) & $31(9)$ \\
\hline \multicolumn{2}{|l|}{ Resection of other organs (except spleen) } \\
\hline None & $293(85.4)$ \\
\hline Stomach & $11(3.2)$ \\
\hline Adrenal gland & $4(1.2)$ \\
\hline Liver & $12(3.5)$ \\
\hline Bowel & $7(2)$ \\
\hline $\begin{array}{l}\text { Other (including gallbladder in non-PPPD/PRPD } \\
\text { procedures, etc.) }\end{array}$ & $26(7.6)$ \\
\hline \multicolumn{2}{|c|}{$\begin{array}{l}\text { ASA American Society of Anaesthesiology, BMI body mass index, IPMN in- } \\
\text { traductal papillary mucinous neoplasm, NET neuroendocrine tumour, } \\
\text { PanIN pancreatic intraepithelial neoplasia, } P P P D \text { pylorus-preserving pan- } \\
\text { creatoduodenectomy, } P R P D \text { pylorus-resecting pancreatoduodenectomy, } \\
P V \text { portal vein, SMV superior mesenteric vein, VC vena cava }\end{array}$} \\
\hline
\end{tabular}


Fig. 2 Number of patients per year undergoing pancreatic resection in our unit according to type of procedure (grouped). $P P P D$ pylorus-preserving pancreatoduodenectomy, PRPD pylorus-resecting pancreatoduodenectomy

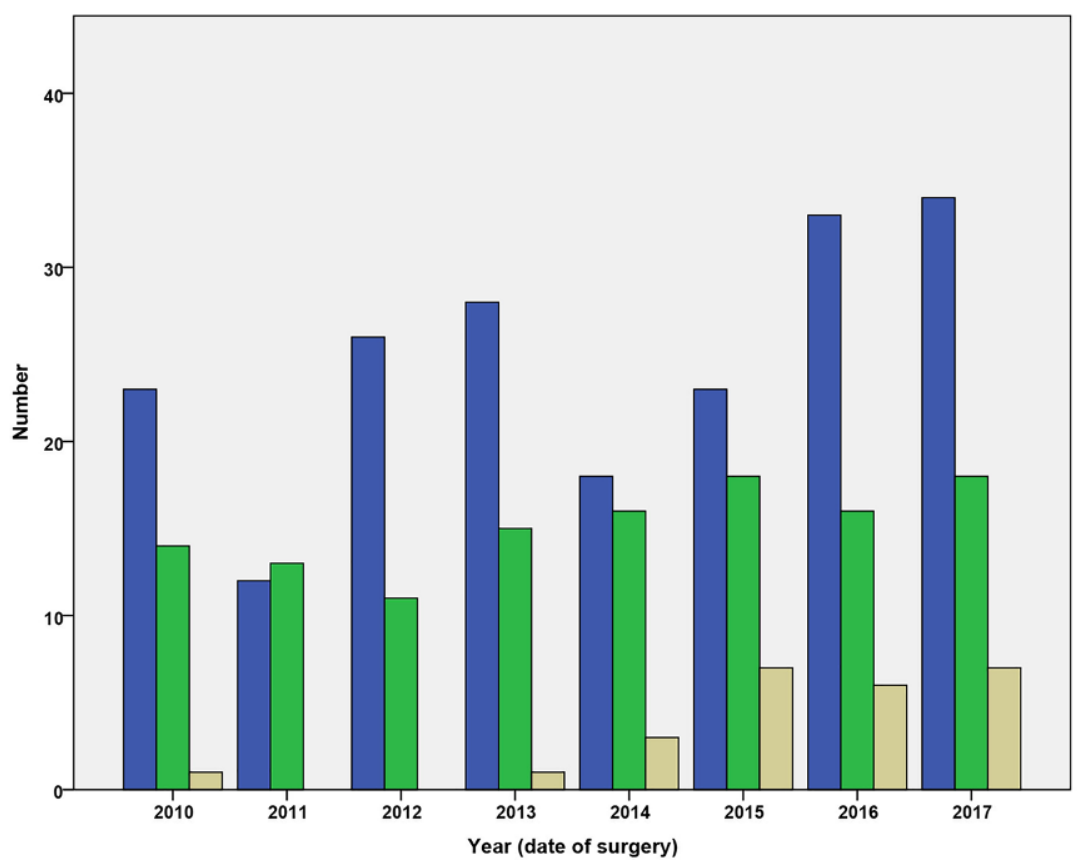

Type of resection
(grouped)

PPPD or PRPD

Distal resections

Dothers

Table 3 Perioperative outcome according to type of resection

\begin{tabular}{|c|c|c|c|c|}
\hline & \multicolumn{3}{|l|}{$n(\%)$} & \multirow[t]{2}{*}{$p$-value } \\
\hline & Pancreatoduodenectomy & Distal resections & Others & \\
\hline \multicolumn{5}{|l|}{ Overall complications } \\
\hline Morbidity (90-day) & $137(69.5)$ & $72(59.5)$ & $18(72)$ & 0.151 \\
\hline Severe morbidity $(C-D>3 a)$ & $44(22.3)$ & $26(21.5)$ & $7(28)$ & 0.807 \\
\hline Mortality (90-day) & $5(2.5)$ & $2(1.7)$ & $0(0)$ & 0.832 \\
\hline \multicolumn{5}{|l|}{ Clinically relevant $P O P F$} \\
\hline Grade $B / C$ & $26(13.2)$ & $32(26.4)$ & $8(32)$ & 0.004 \\
\hline \multicolumn{4}{|l|}{$P P H$} & \multirow[t]{4}{*}{0.270} \\
\hline Grade A & $10(5.1)$ & $6(5)$ & $1(4)$ & \\
\hline Grade B & $16(8.1)$ & $3(2.5)$ & $1(4)$ & \\
\hline Grade C & $16(8.1)$ & $5(4.1)$ & $2(8)$ & \\
\hline \multicolumn{4}{|l|}{$D G E$} & \multirow[t]{4}{*}{0.287} \\
\hline Grade A & $16(8.1)$ & $5(4.1)$ & $1(4)$ & \\
\hline Grade B & $10(5.1)$ & $1(0.8)$ & $0(0)$ & \\
\hline Grade C & $9(4.6)$ & $6(5)$ & $1(4)$ & \\
\hline \multicolumn{5}{|l|}{ Other complications } \\
\hline Intraabdominal fluid collection & $63(32)$ & $48(39.7)$ & $11(44)$ & 0.250 \\
\hline Surgical site infection & $33(16.8)$ & $10(8.3)$ & $3(12)$ & 0.099 \\
\hline Ileus & $7(3.6)$ & $2(1.7)$ & $0(0)$ & 0.641 \\
\hline Pleural effusion & $58(34.5)$ & $17(14.2)$ & $2(8)$ & $<0.001$ \\
\hline \multicolumn{5}{|l|}{ Management variables } \\
\hline Relaparotomy & $31(15.7)$ & $16(13.2)$ & $4(16)$ & 0.811 \\
\hline Postoperative transfusions (missing data $=37$ ) & $56(34.1)$ & $22(18.5)$ & $6(26.1)$ & 0.012 \\
\hline Length of stay: median (SD) & $17(16.9)$ & $14(16.5)$ & $16(8.8)$ & 0.081 \\
\hline Readmission & $34(17.3)$ & $22(18.2)$ & $7(28)$ & 0.405 \\
\hline
\end{tabular}


Table 4 Univariable and multivariable analysis of risk factors for severe complications

\begin{tabular}{|c|c|c|c|c|}
\hline Factor & Univariable analysis & $p$-value & Multivariable analysis & $p$-value \\
\hline Age & $1.01(0.99-1.03)$ & 0.535 & $1.01(0.98-1.03)$ & 0.684 \\
\hline Male gender & $1.99(1.17-3.38)$ & 0.011 & $1.92(1.09-3.38)$ & 0.024 \\
\hline$B M I$ & $1.02(0.96-1.08)$ & 0.525 & $1.02(0.95-1.09)$ & 0.615 \\
\hline ASA score & $1.03(0.67-1.59)$ & 0.879 & a & - \\
\hline \multicolumn{5}{|l|}{ Indication for surgery } \\
\hline Benign tumour & 1.0 (Ref.) & - & 1.0 (Ref.) & - \\
\hline IPMN & $1.56(0.55-4.42)$ & 0.407 & $1.63(0.55-4.82)$ & 0.381 \\
\hline NET & $2.10(0.83-5.32)$ & 0.119 & $1.84(0.70-4.86)$ & 0.219 \\
\hline Carcinoma & $1.65(0.81-3.34)$ & 0.167 & $1.53(0.69-3.39)$ & 0.291 \\
\hline Others (Metastases, etc.) & $1.91(0.58-6.28)$ & 0.290 & $1.34(0.35-5.13)$ & 0.665 \\
\hline \multicolumn{5}{|l|}{ Preoperative conditions } \\
\hline Active smoking & $0.86(0.49-1.52)$ & 0.611 & $0.89(0.47-1.68)$ & 0.711 \\
\hline Alcohol consumption & $0.91(0.54-1.52)$ & 0.707 & $0.84(0.48-1.48)$ & 0.543 \\
\hline Diabetes & $0.76(0.38-1.51)$ & 0.433 & $0.74(0.35-1.55)$ & 0.421 \\
\hline Cardiovascular disease & $1.06(0.63-1.76)$ & 0.839 & $0.97(0.51-1.86)$ & 0.935 \\
\hline Pulmonary disease & $1.08(0.58-2.02)$ & 0.812 & $1.04(0.53-2.06)$ & 0.902 \\
\hline Previous malignancy & $0.85(0.45-1.63)$ & 0.631 & $0.76(0.37-1.58)$ & 0.466 \\
\hline Previous abdominal surgery & $0.94(0.57-1.56)$ & 0.808 & $0.98(0.55-1.73)$ & 0.939 \\
\hline \multicolumn{5}{|l|}{ Type of resection } \\
\hline Pancreatoduodenectomy & 1.0 (Ref.) & - & 1.0 (Ref.) & - \\
\hline Distal resection & $0.95(0.55-1.65)$ & 0.859 & $1.04(0.49-2.19)$ & 0.923 \\
\hline Other & $1.35(0.53-3.45)$ & 0.527 & $1.64(0.58-4.60)$ & 0.351 \\
\hline Laparoscopic resection & $0.76(0.25-2.30)$ & 0.621 & $0.68(0.20-2.34)$ & 0.540 \\
\hline \multicolumn{5}{|l|}{ Additional procedures } \\
\hline Any vascular resection & $1.18(0.56-2.45)$ & 0.664 & $1.07(0.47-2.44)$ & 0.868 \\
\hline Any other organ resection & $0.97(0.47-2.00)$ & 0.934 & $1.11(0.46-2.67)$ & 0.820 \\
\hline
\end{tabular}

were associated with less morbidity (HR 0.42; 95\% CI 0.22-0.82; $p=0.011$; detailed data not included).

\section{Discussion}

Our cohort displays the typical patients undergoing PR in a tertiary referral hospital, where about $50 \%$ of surgical procedures are performed for adenocarcinoma of the pancreas and papilla vateri or distal cholangiocarcinoma as leading pathologies $[11,19$, 20]. Other common indications include pancreatic neuroendocrine neoplasms (11\%) and IPMNs (9\%). In the heterogeneous group of "benign tumours" (22\%) a substantial number of precursor lesions (PanINs) is summarized together with lesions of cystic or solid appearance in preoperative workout, often detected in cases of previous pancreatitis, making correct preoperative diagnosis sometimes challenging. In the literature it has been described that about $5 \%$ of indications of PR represent a false positive diagnosis leading to unnecessary surgery [20]. Despite not having evaluated this issue in detail in the present analysis, we currently follow a patient-oriented treatment selection process especially regarding cystic neoplasia, which often imply controversies in setting indications for invasive treatment $[21,22]$. The current work excluded patients with acute pancreatitis since this entity is nowadays regularly treated by endoscopists and does present with a completely different morbidity rate e.g. in terms of pancreatic fistula and mortality. Nevertheless, we have decided to include resectiontype procedures for chronic pancreatitis to get a complete picture of the landscape of pancreatic surgery in our unit. However, this subgroup of patients represents a small number of only 7 cases $(2.1 \%)$ in 8 years with no mortality and a morbidity rate comparable to the overall cohort (57\%).

In general, regarding the primary endpoint of this study concerning 90-day morbidity (66\%) and mortality $(2 \%)$ rates, we have shown that outcomes after PR in an Austrian high-volume centre are in line with current internationally published results of well-known expert institutions. A number of previous publications reported that postoperative mortality nowadays remains below $4 \%$ after PR when performed in experienced centres [2]. Interestingly, a recent study from Germany suggested that in-hospital mortality following pancreatic surgery is in fact much higher when 
systematically evaluated on a nationwide level compared to single centre data [23]. In this study, the overall mortality exceeded $10 \%$ in one of the most developed health care systems of the world. This clearly shows that retrospective single-centre reports are not necessarily transferable to official national outcome data. Nevertheless, a dramatic difference in mortality has been described in a landmark paper by Birkmeyer et al. when comparing low-volume with highvolume hospitals, with a mortality rate of $16.3 \%$ versus $3.8 \%$ [24]. The volume of hospitals was defined by criteria established by the Leapfrog Group, which also included several non-surgical categories such as permanent availability of a fully equipped intensive care unit [25]. Regarding number of PR, high-volume hospitals were defined performing at least 11 resections annually [26]. Accordingly, the correct implementation of the Leapfrog criteria would have prevented an estimated 177 deaths from pancreatic resections in 2000 in the United States alone [25]. Despite slow nationwide implementation in Austria, the current trend of worldwide centralisation in specialised pancreatic surgery is also observable in our unit, with a significantly increasing number of PR per year, currently surpassing 70 resections in 2018.

In our study, while 90 -day mortality with $2 \%$ was in the lower range of outcomes reported by others $[2,6]$, overall morbidity was substantial with $66 \%$ of patients experiencing any type of complication. Since two-thirds of these complications were graded mild according to Clavien-Dindo $(<3 \mathrm{~b})$, the high morbidity rate first and foremost underlines the importance of exact documentation to deliver a realistic clinical outcome picture. In our institution, we have gradually implemented a prospective documentation system within the last years, hereby not only systematically rating complications already during the hospital stay but also listing morbidity including grading (ClavienDindo) and management in every individual discharge letter to increase transparency. Besides the obvious scientific value, this also helps with rapid assessment in case of readmission, which was necessary in almost every fourth patient, despite an initial median length of stay of 15 days. Our readmission rate lies within internationally reported numbers ranging between 11 and 53\% after PR [27-29]. Studies confirmed that postoperative complications, like POPF, DGE and wound infections remain the most common cause for readmission $[27,30]$. In this study, we did not systematically analyse the reasons for readmission, however sequelae of pancreatic fistula including intraabdominal fluid retention or infection remain the leading causes at our department. Other reasons for readmission were subileus, pancreatic stent issues, development of pseudocysts, colonic fistula, generalized abdominal pain, pseudoaneurysm, infected hematoma and bleeding after drainage removal.

In our cohort, severe complications occurred in $22 \%$ of patients, congruent to rates of over $20 \%$ in the recent literature [31]. One of the most frequent surgical complications at our department was clinically relevant POPF, which was observed in 66 patients (19.3\%; type B: $15.2 \%$, type C: $4.1 \%$ ), ranging within internationally described rates of $10-35 \%$ [2, 32]. POPF remains a major problem with regard to risk for other complications and increasing healthcare costs for prolonged hospitalization or readmission [33, 34]. The most important risk factors for POPF after distal pancreatectomy described in the literature are: younger age, increased BMI, soft pancreatic parenchyma, diabetes mellitus, disease pathology as well as volume of the pancreatic remnant [35]. Since we have not systematically examined pancreatic parenchyma texture and remnant volume, we have not evaluated risk factors for POPF in this study.

A further common complication in our patient cohort was PPH recorded in $17.5 \%$ of patients (grade A: $5 \%$; grade $\mathrm{B}$ : $5.8 \%$; grade $\mathrm{C}: 6.7 \%$ ). This rate is higher to others, describing rates of $7 \%$ in high volume centres [36]. Early postoperative bleeding occurs mostly due to technical errors, while late bleedings are often associated with POPF related to arterial origin due to vascular erosion or pseudoaneurysm [2, 37]. Although not evaluated in detail, the rather higher rate of $\mathrm{PPH}$ in our institution might be a consequence of previous changes in pancreatic anastomosis technique for PPPD, frequent necessity of vascular resections $(12.8 \%)$ or extensive lymphadenectomy. In the literature, the described success rate for interventional/non-surgical management of PPH lies around $50 \%$ [38]. In our cohort, bleeding necessitated relaparotomy in $58 \%$ during the further course, while only $6 \%$ of patients without PPH underwent relaparotomy within the same hospital stay.

Delayed gastric emptying represents the third typical and frequent complication following PR, occurring in $19-57 \%$ [15]. DGE is not only a frequent complication after pancreatoduodenectomy, but it is also seen in distal pancreatectomy. The study from Glowka et al. reported an incidence of $24 \%$ for DGE after distal pancreatectomy [39]. In our patient's cohort, the rate for DGE was $14.3 \%$. Of all complications specific for PR, DGE probably represents the one which is most demanding to be reconstructed from patient records during retrospective analysis. Therefore, DGE rates in our cohort may be underestimated, especially in the early years of this study. In general, DGE causes significantly longer hospital stays, and it seems to be more common after resection for malignant tumours as well as being associated with other major complications [39]. Glowka et al. identified a statistically significant correlation between POPF and DGE. This is in line with our observation were $22.9 \%$ of patients with any POPF developed DGE compared to $11.5 \%$ without underlying POPF $(p=0.010)$. Glowka et al. proposed that prevention of pancreatic fistula might reduce the incidence of DGE, particularly in patients with malignancy [39]. 
FTR has previously been identified as a crucial factor leading to mortality after major surgery including pancreatic resections, especially when several complications accumulate during the postoperative course [40]. In our cohort, despite frequent overall complications, the postoperative mortality was comparably low, resulting in an overall FTR rate of $2.2 \%$. In a recent nationwide time-trend analysis between 2000 and 2011 from the United States of America (USA) a significant decrease in risk-adjusted mortality from 10 to $4 \%$ across all hospitals has been recorded. Intriguingly, the authors showed that by increasing the median hospital volume over the past decade, FTR rates were substantially improved, especially in low (15 to $11 \%$ ) and intermediate volume (11 to $7 \%$ ) hospitals [41], while it remained stable with about 6-7\% in high-volume hospitals, which were defined as units performing 100 or more pancreatic resections per year. When looking at the latest numbers of annual resections per hospital performed in our country (Fig. 1), further efforts in centralization in Austria are indicated to decrease the current nationwide mortality rates of $7.5 \%$ recorded in 2017 . Almost $80 \%$ of all Austrian departments performing pancreatic surgery achieved less than 30 procedures per year, resulting in an in-hospital mortality of $10 \%$ compared to $5.8 \%$ in experienced units with 30 or more procedures. Accordingly, in our opinion, the minimum annual number of at least 10 pancreatic procedures per hospital currently proposed in the national healthcare strategy should be increased to at least 30 procedures in order to lower national mortality rates below $5 \%$.

In further analyses, we were able to identify male gender as the major risk factor for severe complications, while higher BMI and resections other than distal pancreatectomy were associated with increased overall morbidity. This gender aspect finding is in line with McPhee et al. who observed that male patients had a significantly higher morbidity and mortality rate compared with female patients especially after distal pancreatectomy [42]. However, the main reasons are unclear, especially since in comparable literature, gender differences were reviewed only regarding the overall frequencies of complications without details on types of morbidity and also adjustment for comorbidities or other risk factors was lacking.

In summary, clear advances in terms of postoperative management after PR in several centres in Austria including our unit result in mortality comparable to high-volume centres in other countries. However, postoperative morbidity in this field still remains high and failure to-rescue might represent a relevant issue especially in low-volume hospitals. Therefore, further efforts towards centralization but also improvement of prevention and management of POPF and $\mathrm{PPH}$ are necessary. These specific complications imply a substantial risk for sequelae, often necessitate relaparotomy or readmission, cause a potentially threatful burden for affected patients and represent a major cause for mortality and healthcare costs after pancreatic surgery.

Funding Open access funding for this publication was granted by the Medical University of Innsbruck and the University of Innsbruck.

Conflict of interest B. Cardini, F. Primavesi, M. Maglione, J. Oberschmied, L. Guschlbauer, S. Gasteiger, S. Kuscher, T. Resch, R. Oberhuber, C. Margreiter, S. Schneeberger, D. Öfner and S. Stättner declare that they have no competing interests.

Open Access This article is distributed under the terms of the Creative Commons Attribution 4.0 International License (http://creativecommons.org/licenses/by/4.0/), which permits unrestricted use, distribution, and reproduction in any medium, provided you give appropriate credit to the original author(s) and the source, provide a link to the Creative Commons license, and indicate if changes were made.

\section{References}

1. Kunstman JW, Goldman DA, Gönen M, etal. Outcomes after pancreatectomy with routine pasireotide usage. J Am Coll Surg. 2018;20:S30.

2. Lermite E, Sommacale D, Piardi T, et al. Complications after pancreatic resection: diagnosis, prevention and management. Clin Res Hepatol Gastroenterol. 2013;37(3):230-9.

3. Dusch N, Lietzmann A, Barthels F, Niedergethmann M, Rückert F, Wilhelm TJ, International Study Group of PancreaticSurgery Definitions for Postpancreatectomy Complications. Applicability at a high-volume center. Scand J Surg. 2017;106(3):216-23.

4. Chen BP, Bennett S, Bertens KA, Balaa FK, Martel G. Use and acceptance of the International Study Group for Pancreatic Fistula (ISGPF) definition and criteria in the surgical literature. HPB (Oxford). 2018;20(1):69-75.

5. Alp N, Channon K. Regulation of endothelial nitric oxide synthase by tetrahydrobiopterin in vascular disease. Arterioscler Thromb Vasc Biol. 2004;24(3):413-20.

6. Krautz C, Nimptsch U, Weber GF, Mansky T, Grützmann R. Effect of hospital volume on in-hospital morbidity and mortality following pancreatic surgery in Germany. Ann Surg. 2018;267(3):411-7.

7. Federal Ministry for Labour Social Affairs Health and Consumer Protection Austria. Procedure and Mortality Rates after Pancreatic Surgery from the Austrian Inpatient Quality Indicators (A-IQI). 2017. https:// www.sozialministerium.at/siteEN/Health/Health_care_ system/Quality_and_Patient_Safety/.Accessed 01.2019.

8. Schindl M, Fugger R, Gotzinger P, et al. Randomized clinical trial of the effect of a fibrin sealant patch on pancreatic fistula formation after pancreatoduodenectomy. Br J Surg. 2018;105(7):811-9.

9. Gangl O, Sahora K, Kornprat P, et al. Preparing for prospective clinical trials: a national initiative of an excellence registry for consecutive pancreatic cancer resections. World J Surg. 2014;38(2):456-62.

10. Primavesi F, Klieser E, Cardini B, et al. Exploring the surgicallandscape of pancreatic neuroendocrineneoplasia in Austria: Results from the ASSO pNEN study group. Eur J Surg Oncol. 2018;45(2):198-206.

11. Gangl O, Froschl U, Hofer W, Huber J, Sautner T, Fugger R. Unplanned reoperation and reintervention after pancreatic resections: an analysis of risk factors. World J Surg. 2011;35(10):2306-14. 
12. Wagner D, Marsoner K, Tomberger A, et al. Low skeletal muscle mass outperforms the Charlson Comorbidity Index in risk prediction in patients undergoing pancreatic resections. Eur J Surg Oncol. 2018;44(5):658-63.

13. Marsoner K, Haybaeck J, Csengeri D, et al. Pancreatic resection for intraductal papillary mucinous neoplasm-a thirteen-year single center experience. BMC Cancer. 2016;16(1):844.

14. Bassi C, Dervenis C, Butturini G, et al. Postoperative pancreatic fistula: an international study group (ISGPF) definition. Surgery. 2005;138(1):8-13.

15. Wente MN, Bassi C, Dervenis C, et al. Delayed gastric emptying (DGE) after pancreatic surgery: a suggested definition by the International Study Group of Pancreatic Surgery (ISGPS). Surgery. 2007;142(5):761-8.

16. Wente MN, Veit JA, Bassi C, et al. Postpancreatectomy hemorrhage (PPH): an International Study Group of Pancreatic Surgery (ISGPS) definition. Surgery. 2007;142(1):20-5.

17. Statistik-Austria. Statistics Austria Mortality Register 2017. 2017. http://www.statistik.at.

18. Tamirisa NP, Parmar AD, Vargas GM, et al. Relative contributions of complications and failure to rescue on mortality in older patients undergoing pancreatectomy. Ann Surg. 2016;263(2):385-91.

19. Strobel O, Neoptolemos J, Jäger D, Büchler MW. Optimizing the outcomes of pancreatic cancer surgery. Nat Rev Clin Oncol. 2019;16(1):11-26.

20. Birnbaum DJ, Gaujoux S, Berbis J, et al. Surgery for pancreatic neoplasms: How accurate are our surgical indications? Surgery. 2017;162(1):112-9.

21. Pérez-Cuadrado-Robles E, Uribarri-González L, Borbath I, Vila JJ, López-López S, Deprez PH. Risk of advanced lesions in patients with branch-duct IPMN and relative indications for surgery according to European evidencebased guidelines. Dig Liver Dis. 2018; https://doi.org/10. 1016/j.dld.2018.11.028.

22. Mihaljevic A, Al-Saeedi M, Hackert T. Pancreatic surgery: we need clear definitions. Langenbecks Arch Surg. 2018;404(2):159-65.

23. Nimptsch U, Krautz C, Weber GF, Mansky T, Grutzmann R. Nationwide in-hospital mortality following pancreatic surgery in Germany is higher than anticipated. Ann Surg. 2016;264(6):1082-90.

24. Birkmeyer JD, Siewers AE, Finlayson EV, et al. Hospital volume and surgical mortality in the United States. N Engl J Med. 2002;346(15):1128-37.

25. Birkmeyer JD, Dimick JB. Potential benefits of the new Leapfrog standards: effect of process and outcomes measures. Surgery. 2004;135(6):569-75.

26. BirkmeyerJD, StukelTA, Siewers AE, Goodney PP, Wennberg DE, Lucas FL. Surgeon volume and operative mortality in the United States. NEngl J Med. 2003;349(22):2117-27.

27. Kent TS, Sachs TE, Callery MP, Vollmer CM Jr. Readmission after major pancreatic resection: a necessary evil? J Am Coll Surg. 2011;213(4):515-23.
28. Reddy DM, Townsend CM Jr., Kuo YF, Freeman JL, Goodwin JS, Riall TS. Readmission after pancreatectomy for pancreatic cancer in Medicare patients. J Gastrointest Surg. 2009;13(11):1963-74. discussion 74-5.

29. Balcom JHt, Rattner DW, WarshawAL, Chang Y, Fernandezdel Castillo C. Ten-year experience with 733 pancreatic resections: changingindications, older patients, and decreasinglength of hospitalization. Arch Surg. 2001;136(4):391-8.

30. Glass CC, GondekSP,VollmerCM, CalleryMP, KentTS. Readmission following pancreatectomy: what can be improved? HPB (Oxford). 2013;15(9):703-8.

31. Pugalenthi A, Protic M, Gonen M, et al. Postoperative complications and overall survival after pancreaticoduodenectomy for pancreatic ductal adenocarcinoma. J Surg Oncol. 2016;113(2):188-93.

32. Schoellhammer HF, Fong Y, Gagandeep S. Techniques for prevention of pancreatic leak after pancreatectomy. HepatobiliarySurg Nutr. 2014;3(5):276-87.

33. Tjaden C, HinzU, Hassenpflug M, etal. Fluid collection after distal pancreatectomy: a frequent finding. HPB (Oxford). 2016;18(1):35-40.

34. Hackert T, Werner J, Buchler MW. Postoperative pancreatic fistula. surgeon. 2011;9(4):211-7.

35. McMillan MT, Vollmer CM Jr. Predictive factors for pancreatic fistula following pancreatectomy. Langenbecks Arch Surg. 2014;399(7):811-24.

36. Ansari D, Tingstedt B, Lindell G, Keussen I, Andersson R. Hemorrhage after major pancreatic resection: incidence, risk factors, management, and outcome. Scand J Surg. 2017;106(1):47-53.

37. de Castro SM, Busch OR, Gouma DJ. Management of bleeding and leakage after pancreatic surgery. Best Pract Res Clin Gastroenterol. 2004;18(5):847-64.

38. Wellner UF, Kulemann B, Lapshyn H, et al. ostpancreatectomy hemorrhage-incidence, treatment, and risk factors in over 1,000 pancreatic resections. J Gastrointest Surg. 2014;18(3):464-75.

39. Glowka TR, von Websky M, Pantelis D, et al. Risk factors for delayed gastric emptying following distal pancreatectomy. Langenbecks Arch Surg. 2016;401(2):161-7.

40. Varley PR, Geller DA, Tsung A. Factors influencing failure to rescue after pancreaticoduodenectomy: a national surgical quality improvement project perspective. J Surg Res. 2017;214:131-9.

41. Amini N, Spolverato G, Kim Y, Pawlik TM. Trends in Hospital Volume and Failure to Rescue for Pancreatic Surgery. JGastrointest Surg. 2015;19(9):1581-92.

42. McPhee JT, Hill JS, Whalen GF, et al. Perioperative mortality for pancreatectomy: a national perspective. Ann Surg. 2007;246(2):246-53.

Publisher's Note Springer Nature remains neutral with regard to jurisdictional claims in published maps and institutional affiliations. 